\title{
Ammonia-oxidizing archaea: important players in paddy rhizosphere soil?
}

\author{
Xue-Ping Chen, Yong-Guan Zhu, ${ }^{*}$ Yue Xia, \\ Ju-Pei Shen and Ji-Zheng He* \\ Research Center for Eco-environmental Sciences, \\ Chinese Academy of Sciences, Beijing 100085, China.
}

\section{Summary}

The diversity (richness and community composition) of ammonia-oxidizing archaea (AOA) and bacteria $(A O B)$ in paddy soil with different nitrogen (N) fertilizer amendments for 5 weeks were investigated using quantitative real-time polymerase chain reaction, denaturing gradient gel electrophoresis (DGGE) jand clone library analysis based on the ammonia monooxygenase $\alpha$-subunit (amoA) gene. Ammoniaoxidizing archaea predominated among ammoniaoxidizing prokaryotes in the paddy soil, and the AOA:AOB DNA-targeted amoA gene ratios ranged from 1.2 to 69.3. Ammonia-oxidizing archaea were more abundant in the rhizosphere than in bulk soil. Rice cultivation led to greater abundance of $A O A$ than $A O B$ amoA gene copies and to differences in AOA and $A O B$ community composition. These results show that AOA is dominant in the rhizosphere paddy soil in this study, and we assume that AOA were influenced more by exudation from rice root (e.g. oxygen, carbon dioxide) than AOB.

\section{Introduction}

The supply of nitrogen $(\mathrm{N})$ fertilizer to paddy fields is recognized as a major factor determining rice yields (Cassman et al., 1993). Although ammonium is considered as the major form to which rice is especially adapted (Shen, 1969; Wang et al., 1993), it has been suggested that rice may absorb significant amounts of nitrate formed by nitrification of ammonium in the rhizosphere (Kronzucker et al., 2000). The ammonia monooxygenase $\alpha$-subunit (amoA) gene, which is responsible for catalysing the rate-limiting step in autotrophic bacterial ammonia oxidation, has been used extensively as a molecular marker for cultivationindependent studies of ammonia-oxidizing bacteria

Received 29 January, 2008; accepted 20 February, 2008. *For correspondence. E-mail ygzhu@ rcees.ac.cn; jzhe@ rcees.ac.cn; Tel. (+86) 10 62936940; Fax (+86) 1062923563.
(AOB) communities. Some archaea may carry amoA genes, as demonstrated by Venter and colleagues (2004) using whole genome shotgun analysis of DNA sequences derived from the Sargasso Sea. Further, Schleper and colleagues (2005) using fosmids derived from soil Crenarchaeota libraries identified a Sargasso Sea-like amoA homologue, suggesting that archaea capable of ammonia oxidation may be present in soils. Recently, a definitive link between this novel amoA and archaeal ammonia oxidation was established by isolation of an ammonia-oxidizing member of the marine group 1 Crenarchaeota (Könneke et al., 2005). Thus it is likely that ammonia oxidation is carried out by both ammonia-oxidizing archaea (AOA) and AOB. Considering the ubiquity of $A O A$ in multiplex habitats, such as oxic and suboxic marine water bodies, estuarine sediments and soils (Francis et al., 2005), it seemed possible that AOA could also be present in paddy soil. Ammonia-oxidizing archaea have been demonstrated to be the dominant group among ammonia-oxidizing prokaryotes in the ocean (Wuchter et al., 2006) and in soils (Leininger et al., 2006), but the relative abundance of $A O A$ and $A O B$ in paddy soil has not been investigated so far.

The rice paddy microcosm is a useful system for the description and prediction of microbiological and biogeochemical processes in wetland habitats. Oxygen deplete rapidly in a few millimetres beneath the soil surface, leaving the bulk soil anoxic. However, oxygen is considered to leak from aerenchymatous tissue in rice creating an oxic rhizosphere within the anoxic bulk soil (Revsbech et al., 1999). Aerenchyma, a porous tissue which may be an adaptation to anoxic root environment in rice plants, establishes a gas channel between the atmosphere and the root tissue. It has been suggested that oxygen released from rice roots may support aerobic microbial processes (e.g. nitrification) (Arth et al., 1998; Brune et al., 2000). However, a less stereotype information is available regarding the abundance, composition and activity of populations of $\mathrm{AOA}$ and $\mathrm{AOB}$ occurring in the rice rhizosphere.

Environmental functional genes based on mRNA are related to activity, and sequence heterogeneity may be related to phylogenetic distance (Wawer and Muyzer, 1995). Aoi and colleagues (2004) has demonstrated that amoA mRNA showed sensitive response to ammonia 


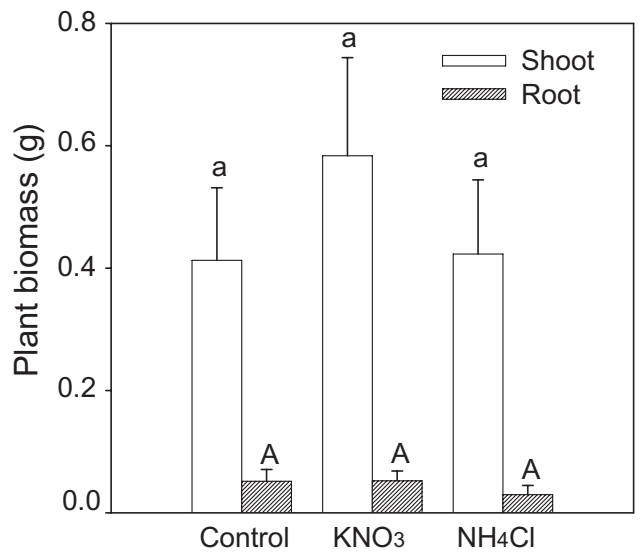

Fig. 1. Plant biomass after 5 weeks of growing in a greenhouse of potting soil with different nitrogen fertilizer amendments. Error bars indicated standard deviation. Within shoot and root biomass, means (mean $\pm \mathrm{SE}, n=4$ ) followed by the same letter are not significantly different at $P<0.05$

oxidation activity, which can be used as a biomarker of ammonia oxidation activity in wastewater treatment processes where many bacterial species exist. Therefore, we assumed that amoA mRNA level was also correlated with ammonia oxidation activity in paddy soil. In addition, recently unequivocal data have indicated the strong rice root-promoted nitrification and active AOB in rice rhizosphere (Li et al., 2008). In this study, we analysed the relative abundance of $A O A$ and $A O B$ in the rice rhizosphere and bulk soil using quantitative real-time polymerase chain reaction (PCR) based on DNA and CDNA reverse transcribed from RNA. The community structures of $A O A$ and $A O B$ from soil were also detected using PCR-denaturing gradient gel electrophoresis (DGGE) approach based on the amoA gene.

\section{Results}

Shoot and root dry weights of rice plants grown with nitrate addition appeared only slightly higher than those from the control and ammonia treatments. However, differences between these treatments were not significant (Fig. 1).

\section{amoA-targeted quantitative real-time PCR assay}

The DNA-targeted archaeal amoA gene copy numbers in the paddy soil ranged from $1.0 \times 10^{6}$ to $1.8 \times 10^{7}$ per gram dry weight of soil, and the DNA-targeted bacterial amoA gene ranged from $1.6 \times 10^{5}$ to $9.8 \times 10^{6}$ per gram dry weight of soil (Fig. 2A). The AOA:AOB amoA gene ratios ranged from 1.2 to 69.3. According to paired-sample $t$-test, both cDNA-targeted archaeal and bacterial amoA gene copy numbers were significantly higher than those from DNA-targeted in each soil sample (Fig. 2B). Interestingly, cDNA-targeted amoA gene ratio of $\mathrm{AOA}$ to $\mathrm{AOB}$ was correlated well with DNA-targeted quantitative measurements, and the maximal $A O A: A O B$ amoA gene ratio was 22.9.

The DNA-targeted archaeal amoA gene copy numbers in the soil samples without rice were significantly lower than those in soil with rice except for the control (Fig. 2A). Furthermore, DNA-targeted archaeal amoA copy numbers in the rhizosphere soil were much higher than those in the bulk soil, irrespective of $\mathrm{N}$ treatments. In addition, the DNA-targeted archeal amoA gene copy numbers in the rhizosphere soil with the addition of
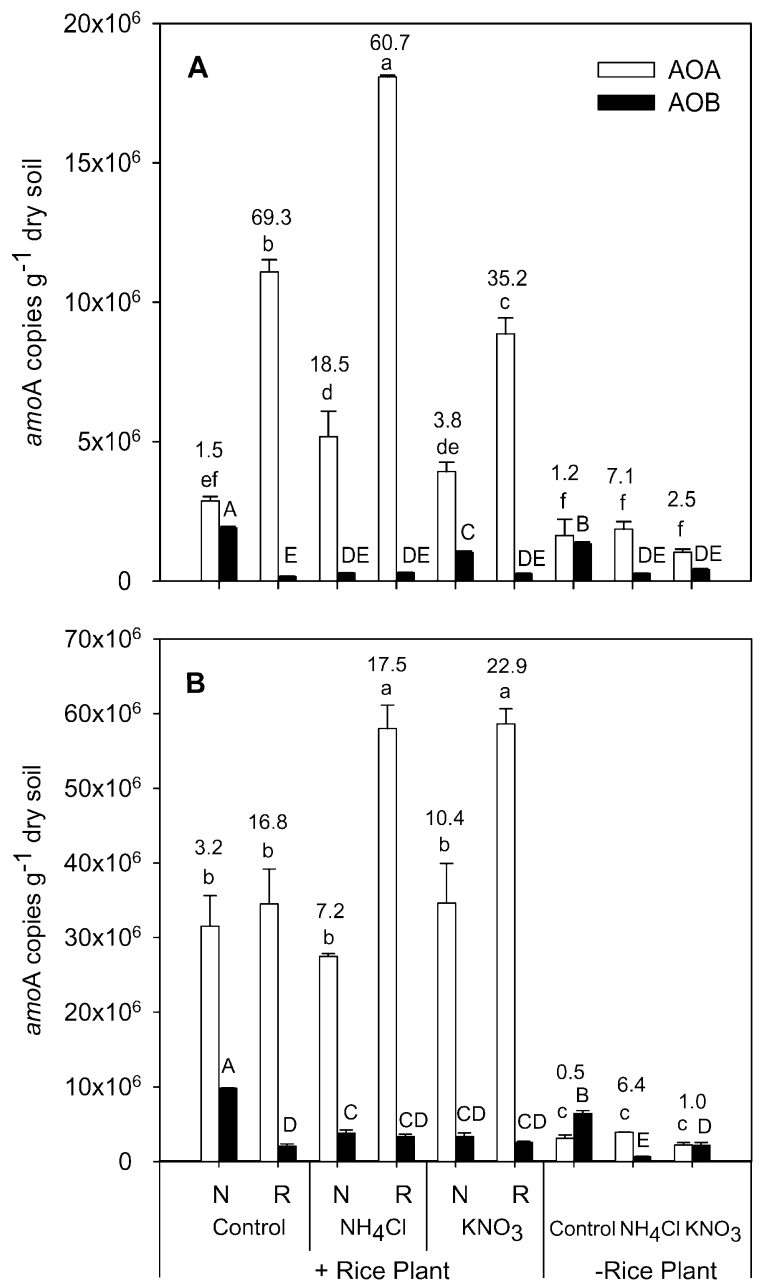

Fig. 2. Abundance of $A O A$ and $A O B$ in paddy soil with different nitrogen fertilizer amendments expressed as DNA-targeted $(A)$ and cDNA-targeted (B) amoA copy numbers per gram dry weight of soil respectively. Ratios of $A O A$ to $A O B$ amoA copies are shown at the top columns with each treatment. Error bars indicate standard deviation. N, bulk; R, rhizosphere. Within DNA-targeted (A) and cDNA-targeted (B) archaeal and bacterial amoA copy numbers, means (mean $\pm \mathrm{SE}, n=4$ ) followed by the same letter are not significantly different at $P<0.05$. 


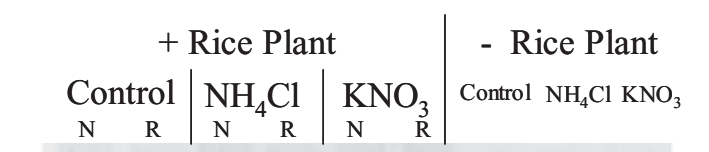

A

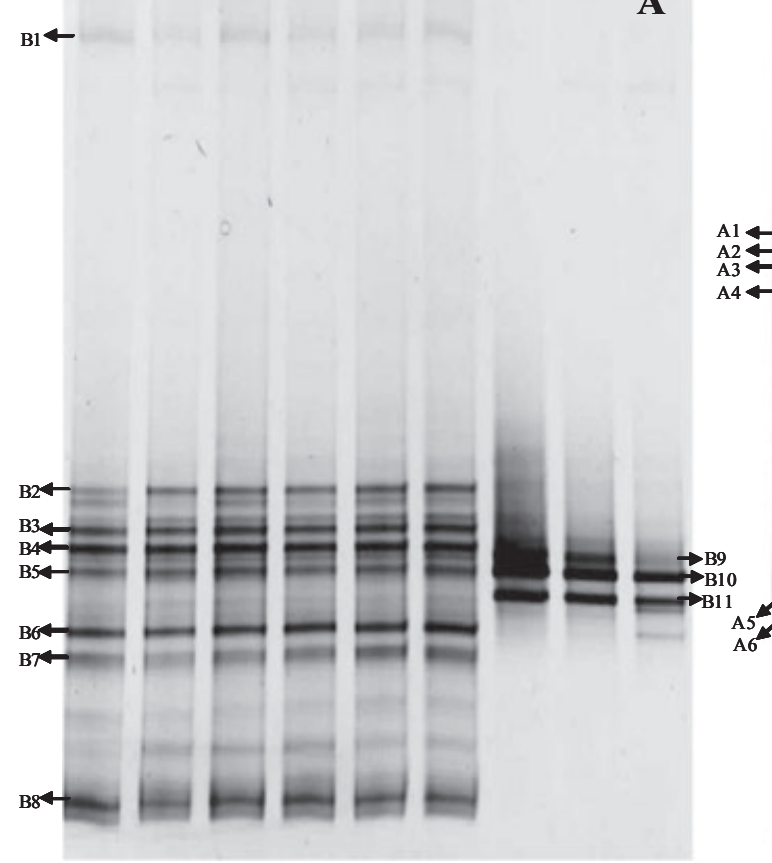

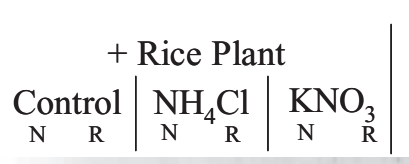

A - Rice Plant Control $\mathrm{NH}_{4} \mathrm{Cl} \mathrm{KNO}_{3}$

B

Fig. 3. Denaturing gradient gel electrophoresis (DGGE) analysis of the predominant PCR-amplified partial cDNA-targeted amoA of $A O B$ (A) and $A O A(B)$ obtained from the paddy soil with different $N$ fertilizer amendments. Respective 11 major AOA and AOB DGGE bands that showed unique positions in the gels were observed and excised. $\mathrm{N}$, bulk; R, rhizosphere.

ammonia were significantly higher than the control. Interestingly, archaeal amoA gene copy numbers varied little in the soil with different $\mathrm{N}$ amendments without rice plants. However, there was no significant difference in DNAtargeted bacterial amo $A$ gene copy numbers in all soil samples except the control with and without rice. The variation in DNA-targeted amoA gene copy numbers was confirmed by cDNA-targeted analysis. The cDNAtargeted archaeal amoA gene copy numbers in the soil samples with rice were significantly higher than those in soil without rice (Fig. 2B). CDNA-targeted archaeal amoA copy numbers in the rhizosphere soil were significantly higher than those in the bulk soil with ammonia and nitrate treatments. The cDNA-targeted archeal amoA gene copy numbers in the rhizosphere soil with the addition of ammonia and nitrate were significantly higher than the control. There was no significant difference in the soils without rice. Except for the control with and without rice, the DNA-targeted bacterial amoA gene abundance did not vary significantly.

\section{DGGE profiles of archaeal and bacterial communities}

Denaturing gradient gel electrophoresis analysis was performed on archaeal and bacterial amoA PCR products obtained from cDNA generated using reverse transcription (RT)-PCR products (Fig. 3). Reproducible profiles were obtained from both templates for all soil treatments, and DNA- and CDNA-derived profiles of both AOA and $A O B$ were indistinguishable, and DNA-profile data were not shown. The numbered bands with two replicates with the same mobility in the DGGE gels were excised for sequencing, and cloned sequences obtained from different bands of the same mobility had high homology (> 97\%). One representative sequence from cDNA PCRDGGE pattern was chosen to do phylogenetic analysis (Fig. 4). Both $A O A$ and $A O B$ community profiles in the rhizosphere soil with different $\mathrm{N}$ amendments were indistinguishable with those in bulk soil, while AOB communities in soil without rice plants were clearly different from those with planted rice.

\section{$A O A$ and $A O B$ phylogeny}

Phylogenetic analysis of archaeal amoA gene showed that all sequences were distributed in several subclusters of soil and sediment clusters (Fig. 5). All the sequences detected in the paddy soil without rice plants fell into cluster 1 except for band 7, which belonged to cluster 7 . Interestingly, cluster 7 contained most sequences of archaeal 


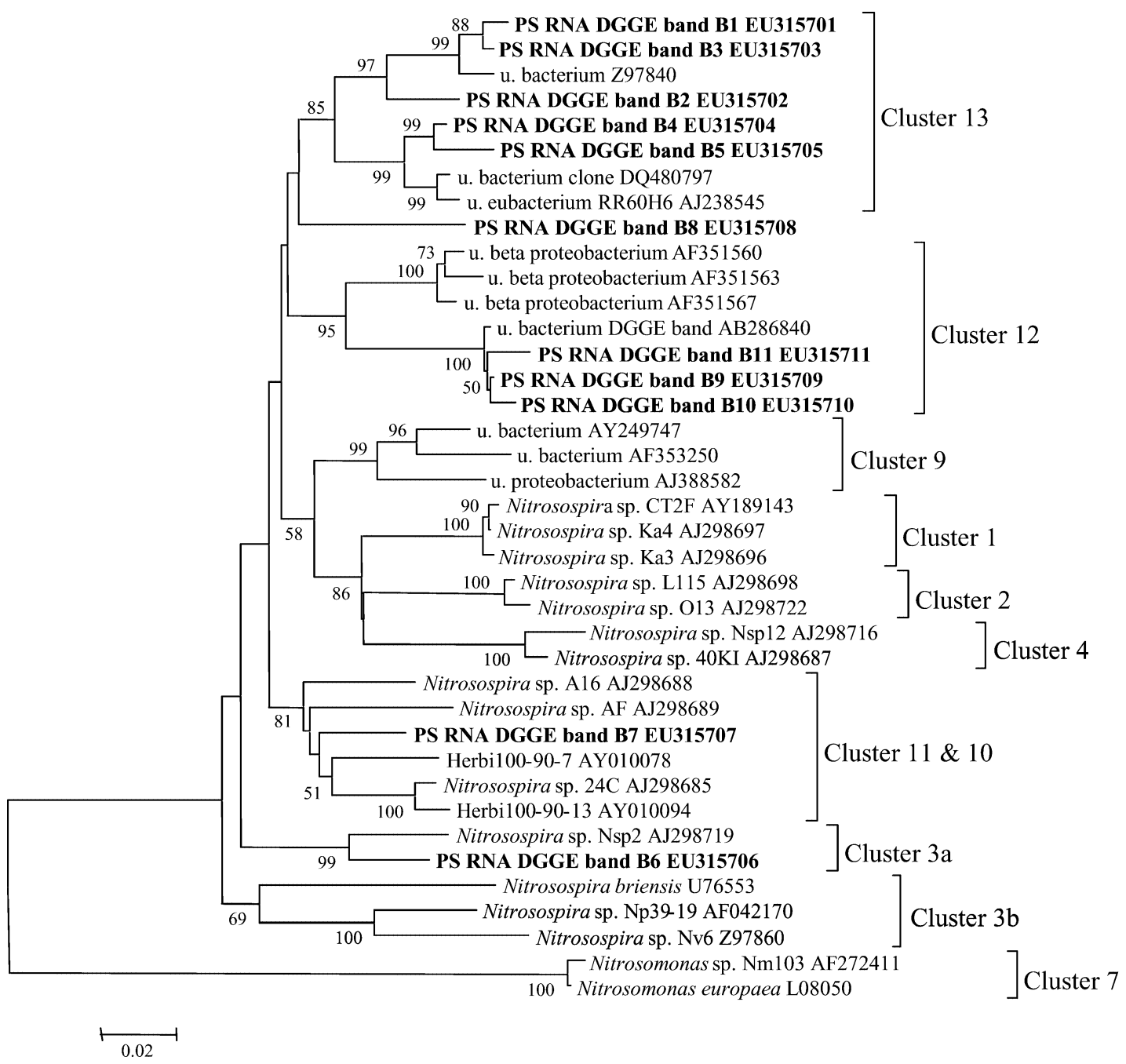

Fig. 4. Phylogenetic analyses of CDNA-targeted bacterial amoA recovered from DGGE bands of paddy soil with different nitrogen fertilizer amendments (shown in bold). The sequences of DNA bacterial amoA DGGE bands that are not mentioned in the tree due to $>99 \%$ amino acid identity to sequences obtained from the RNA bacterial amoA DGGE bands. The scale bar indicates two changes per 100 amino acid positions.

amoA gene recovered from the soil with rice. While bands 5 and 6 were grouped in cluster 1 and 8 respectively.

Polymerase chain reaction amplification of a $635 \mathrm{bp}$ archaeal amoA fragment was obtained from DNA extracts of the control soil. Approximately 100 clones were selected from the library and re-amplified successfully. A total of 20 archael amoA gene agarose gel patterns of restriction digestion (data not shown), using restriction endonuclease Haelll and Rsal, were obtained. For sequence types that exhibited at least $99 \%$ amino acid similarity to each other, only 12 representative sequences were selected for the construction of trees. Based on those amoA gene sequences and primers cut-off standard with sequences obtained from DGGE bands, 12 representative clone sequences were distributed in eight subclusters in soil/sediment cluster. Sequences from the archaeal amoA clone library of paddy soil in the control were correlated with the recovered DGGE bands.

A neighbour-joining tree was constructed using sequences of bacterial amoA DGGE bands and the related sequences deposited in GenBank (Fig. 5). According to the nomenclature for Nitrosospira amoA clusters as defined by Avrahami and colleagues (2002) and Avrahami and Conrad (2003), all the band sequences appeared to be the genus Nitrosospira, without Nitrosomonas species in the paddy soil. All the sequences in the paddy soil without rice were grouped within cluster 12. Bands 1-5 recovered from the paddy soil with rice were distributed solely in cluster 13. Band 8 , one of the common bands in the soil with rice, was not grouped into any defined cluster. Bands 6 and 7 fell in cluster $3 a$ and cluster 11 and 10 respectively. 


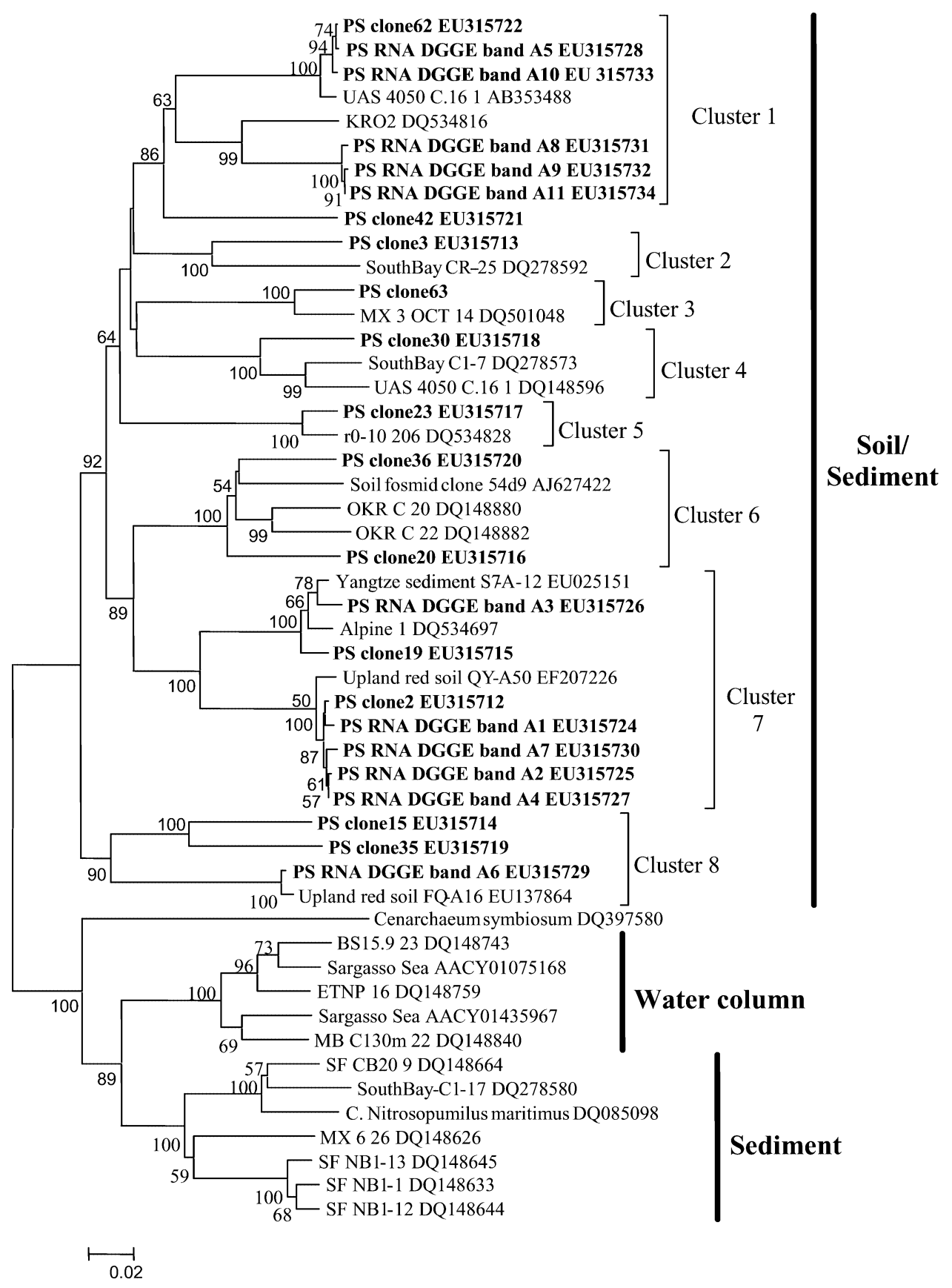

Fig. 5. Phylogenetic relationships among RNA archaeal amoA recovered from DGGE bands of paddy soil with different nitrogen fertilizer amendments and archaeal amoA gene clone library from untreated paddy soil (shown in bold) and previously reported environmental sequences. The sequences of DNA archaeal amoA DGGE bands and partial clone sequences that are not mentioned in the tree due to $>99 \%$ amino acid identity to sequences obtained from the RNA archaeal amoA DGGE bands or another clone sequence. The scale bar indicates two changes per 100 amino acid positions.

\section{Discussion}

Both $\mathrm{AOA}$ and $\mathrm{AOB}$ were highly abundant in paddy soil, based on amoA genes using quantitative real-time PCR methods. The archaeal $a m o A$ gene copy numbers ranged from $1.0 \times 10^{6}$ to $5.9 \times 10^{7}$ per gram dry weight of soil, similar to the numbers determined in an upland red soil using the same primers as in this study, a soil that is commonly considered to be more oxic than paddy soil (He et al., 2007). The emergent rice plants had a strong stimulating effect on the numbers of $A O A$ in the paddy soil. The numbers of DNA archaeal amoA gene copies in 
the rhizosphere were significantly higher than in the bulk soil. It is well known that rice roots release oxygen through aerenchymatous tissue at rates sufficient to support non-specific aerobic microbial processes (Bedford et al., 1991) and aerobic nitrification (Mosier et al., 1990; Arth et al., 1998). In addition, carbon dioxide, which elevated in the rhizosphere due to both root and microbial respiration, would be the carbon source for chemolithoautotrophs. On the contrary, in the bulk soil there would only be microbial respiration but lower oxygen concentrations. Our results suggested that AOA were significantly influenced by exudation from rice roots (e.g. oxygen, carbon dioxide). Although little information of AOA has been published (Könneke et al., 2005; De La Torre et al., 2008), we assumed that carbon source exuded from root would influence AOA if they are heterotrophic. Bowatte and colleagues (2007) investigated the effect of elevated atmospheric $\mathrm{CO}_{2}$ on $\mathrm{AOB}$ communities associated with rice roots; it was expected that $\mathrm{AOB}$ community would be influenced by $\mathrm{CO}_{2}$ exudation from rice root. However, there was no significant difference in bacterial amoA gene copy number in the rhizosphere and the bulk soil. Compared with AOA, the bacterial DNA amoA gene copy numbers were much lower, and the ratio of $A O A$ to $A O B$ ranged from 1.2 to 69.3 , which indicated that archaea dominated in paddy soil. Briones and colleagues (2002) did not obtain significant products of bacterial amoA gene in the rhizosphere soil with rice. Taking into account the extremely low yields of $A O B$ in the bulk soil with different $\mathrm{N}$ treatments, amounts of $A O B$ increased when AOA was relatively lower in the bulk soil of the control and the treatment with nitrate amendment. It is very likely that $A O A$ competed with $A O B$ in the ammonification, and that $A O A$ may be more competitive than AOB for ammonification in rice rhizosphere microenvironment. This may imply that AOA may have a higher affinity for oxygen or carbon dioxide, which may explain their predominance in the rhizosphere.

Despite the great differences in the abundances of $A O A$ between rhizosphere and bulk soils, little difference in both the archaeal and bacterial amoA DGGE patterns was detected between the rhizosphere and the bulk soils with nitrate and ammonia fertilizers. Phylogenetic analysis in the present study based on bacterial amoA identified that Nitrosopira-like species dominated in paddy soil, which was in agreement with a previous study in paddy soil (Bowatte et al., 2006a) or associated weeds in paddy soil (Bowatte et al., 2006b). However, Bowatte and colleagues (2007) also found that both Nitrosospira-like and Nitrosomonas-like AOB sequences were detected on rice roots. Briones and colleagues (2002) further demonstrated that the levels of abundance of Nitrosomonas spp. were different between different cultivars of rice. This might be due to the ability of Nitrosomonas to outcompete
Nitrosospira-like $\mathrm{AOB}$ at high substrate and oxygen concentrations. The phylogenetic tree also revealed that most of the AOB detected here in the paddy soil belong to an undescribed cluster 13 in the rhizosphere and the bulk soil. Previous studies have demonstrated that AOB in the surface soil were dominated by cluster 1 in a Japanese paddy field (Murase et al., 2003), and cluster 7 in a Philippine paddy field (Nicolaisen et al., 2004). These studies indicated that paddy soil can harbour a limited $A O B$ community in comparison with other soils (grassland, meadow, forest soils) (Avrahami et al., 2002; Mintie et al., 2003; Horz et al., 2004). Similar to AOB, all archaeal amo $A$ gene sequences belonged to soil and sediment clusters. In addition, the AOA in the paddy soil with rice plants belonged to one subcluster (cluster 7). It appears that limiting numbers of both $A O A$ and $A O B$, which predominate for the ammonia-oxidizing community in paddy soil, are adapted to life in low-oxygen or periodically anoxic habitats. Bodelier and colleagues (1996) demonstrated that the ammonia-oxidizing communities of grassland soil lost more than $90 \%$ of initial nitrifying capacity upon anoxic incubation, while the ammonia-oxidizing communities in lake sediment started to nitrify within $1 \mathrm{~h}$ upon exposure to oxygen at the level of the initial capacity. From our results, it seems that AOA were more capable to react rapidly to the presence of oxygen in fluctuating oxic and anoxic rhizosphere of rice plants.

To explore more thoroughly the AOA community in paddy soil, an archaeal amoA clone library was generated from the control paddy soil. From the phylogenetic analysis of representative amoA clone sequences, it was observed that clone library satisfactorily covered the archaeal amoA DGGE patterns. However, DGGE separated the predominant species in the community. All of the clone sequences were distributed in different multiplex subclusters in soil sediment cluster, which indicated that AOA community was diverse in paddy soil.

The results based on quantitative real-time PCR and PCR-DGGE showed great differences in the abundances and exactly the same community composition of $A O B$ and $A O A$ in the rhizosphere and bulk soil, which prompted our investigation into the abundance and composition of $A O B$ and $A O A$ populations in the paddy soil without rice plants with different $\mathrm{N}$ amendment. Interestingly, both $\mathrm{AOA}$ and $\mathrm{AOB}$ abundance were kept at a relatively low level in the soil without rice plants, and the phylogenetic analysis also revealed that both AOA and $\mathrm{AOB}$ detected in the paddy soil without rice belonged to a different cluster from that from the paddy soil with rice. Upon anoxic incubation, the AOA community lost nitrifying capacity and an extreme low amoA gene level was detected by quantitative real-time PCR compared with that in soil with rice. Flooded paddy soil without rice plant is generally anoxic except for the upper few millimetres. 
The oxidation of ammonia to nitrite by ammonia-oxidizing bacteria, which are strict aerobic chemolithoautotrophic microorganisms, can only occur in the presence of oxygen and thus would be restricted to the oxic upper few millimetres of flooded soils. However, from the DGGE fingerprints, several species of both $A O A$ and $A O B$, which were grouped within different clusters from that in the paddy soil with rice plants, survived in the paddy soil without rice plants. Molina and colleagues (2007) explored the community structure of $\beta$ class $A O B$ in an oxygen gradient-associated zone with minimum oxygen, and found a clear community shift at the amoA level along the strong oxygen gradient. Our results also provided strong evidence that the presence or absence of oxygen and carbon dioxide (leaked through rice roots) was the major factor determining the changes in $\mathrm{AOA}$ and AOB community structure.

To obtain further evidence for our conclusion, the archaeal populations detected on the DNA level were the metabolically active groups, and an RNA-based approach followed by RT and quantitative real-time PCR and PCRDGGE analysis was applied. The results based on RNA for both rhizosphere and bulk soil with and without rice plants were similar to those obtained based on the DNA analysis. This suggested that the microbial groups detected on the DNA level were the metabolically active populations in the paddy soil. From the result of quantitative real-time PCR based on DNA and RNA, archaeal cDNA-targeted amoA gene copy numbers in the rhizosphere soil with nitrate addition significantly increased, which indicates that nitrate could be denitrified to ammonia in flooding soil and increase archaeal amo $A$ gene expression on the RNA level. Ammonia addition could stimulate both AOA growth and activity compared with the control. From our results, $A O A$ is predominant in the paddy soil; it is therefore necessary to understand the role of $\mathrm{AOA}$ in the rhizosphere, and to further elucidate their interactions with denitrifiers, to better manipulate $\mathrm{N}$ cycling in paddy soil.

\section{Experimental procedures}

\section{Pot experiment}

The paddy soil was obtained from a field located in Shangyu, Zhejiang province (China). Before the experiment, the soil was air-dried and sieved through a $2 \mathrm{~mm}$ mesh. The characteristics of the soil were list as follows: $\mathrm{pH}\left(\mathrm{H}_{2} \mathrm{O}\right), 6$.8; organic matter, $9.32 \mathrm{~g} \mathrm{~kg}^{-1}$; alkali-hydrolysable $\mathrm{N}, 49.9 \mathrm{mg} \mathrm{kg}^{-1}$; available phosphorus, $16.5 \mathrm{mg} \mathrm{kg}^{-1}$. Plants were allowed to grow with different nitrogen treatments: (i) untreated soil (control), (ii) addition of $\mathrm{KNO}_{3}$ and (iii) addition of $\mathrm{NH}_{4} \mathrm{Cl}$, and equimolal potassium as $\mathrm{KCl}$ with treatment of $\mathrm{KNO}_{3}$. Nitrogen (either $1 \mathrm{mM} \mathrm{kg}^{-1}$ soil nitrate or ammonium) was added every week. Rice plants were harvested 1 week after the last fertilization, when soil samples were collected for analyses.
Rice seeds (Oryza sativa L.) cv. Jiahua-1 were disinfected in $30 \% \mathrm{H}_{2} \mathrm{O}_{2}$ (w:w) solution for $10 \mathrm{~min}$, followed by thorough washing with de-ionized water. The seeds were germinated in moist perlite. After 3 weeks, uniform seedlings were selected and transplanted into bags ( $37 \mu \mathrm{m}$ nylon mesh, $7.5 \mathrm{~cm}$ diameter, $10 \mathrm{~cm}$ height, one plant per bag) filled with $0.2 \mathrm{~kg}$ of sieved soil, which were placed in the centre of $1.5 \mathrm{~kg}$ pots, and the gap between nylon bag and PVC pot was filled with $0.8 \mathrm{~kg}$ of soil, the same as the soil into nylon bag. This allowed a separation of root/rhizosphere compartment from a soil compartment. In order to evaluate the influence of the rice plants on the rice paddy soil characteristics, control experiments without rice were incubated with ammonia and nitrate amendments as described above. To eliminate effects of additional $\mathrm{N}$ during the experiment, through $\mathrm{N}_{2}$ fixation by cyanobacteria, for example, the top of the pot was covered by black nylon with a gap to allow the rice to grow.

After transplanting into the PVC pots, the rice plants were grown for 5 weeks in a greenhouse with a 14/10 h light/dark cycle, and the temperature was kept at $25^{\circ} \mathrm{C}$ during the day and $16^{\circ} \mathrm{C}$ during the night, with $70 \%$ relative humidity.

At harvest, the rhizosphere and bulk soil were collected and immediately frozen in liquid $\mathrm{N}_{2}$ and stored at $-80^{\circ} \mathrm{C}$ until required. Analysis was carried out on samples from four separate PVC pots of the same treatment.

\section{DNA and RNA extraction}

DNA was extracted using a FastDNA SPIN Kit for soil (Bio 101, Vista, CA) following the manufacturer's instructions.

RNA was extracted using the bead-beating method developed by Noll and colleagues (2005). The raw extracts of nucleic acids were purified by Quick-clean SPIN filters (Cat. No. 6070-057, Bio 101, Vista, CA) and digested with DNase I (Takara Shuzo, Shiga, Japan) to remove DNA. Performing PCR on RNA samples after DNase treatment confirmed the amplification of RNA templates free of DNA contamination. The first-strand cDNA was synthesized using PrimeScriptTM 1st Strand cDNA Synthesis kit (Takara Shuzo, Shiga, Japan) according to the manufacturer's instruction. Prior to RT, the RNA secondary structure was melted by incubating the RNA samples with random 6 mers primer at $0.25 \mu \mathrm{M}$ at $65^{\circ} \mathrm{C}$ for $5 \mathrm{~min}$. Samples of annealed primer template were snapped on ice, and $10 \mu \mathrm{l}$ of $\mathrm{RT}$ reaction mixture (containing maximum of $500 \mathrm{ng}$ of template RNA, $2 \mu$ l of $5 \times$ PrimeScript buffer and $100 \mathrm{U}$ of PrimeScript RTase supplied by the Kit) was added. Reverse transcription was carried out at $30^{\circ} \mathrm{C}$ for $10 \mathrm{~min}$, $42^{\circ} \mathrm{C}$ for $30 \mathrm{~min}$ and $70^{\circ} \mathrm{C}$ for $15 \mathrm{~min}$ according to instruction.

\section{Construction of archaeal amoA gene fragment libraries}

A clone library of archaeal amoA amplicons obtained from the control soil sample was constructed to analyse the AOA community structure according to Weidner and colleagues (1996). Briefly, after PCR amplification of the archaeal amoA gene of the total DNA extracted from soil samples, gel slices of an agarose gel containing the PCR products were excised, and purified using Agarose Gel DNA Purification Kit (Ver. 2.0, TaKaRa). The purified PCR products were ligated into $p$-GEM T easy vector (Promega, Madison, WI) and then cloned into 
Escherichia coli JM109 (TaKaRa) in accordance with the manufacturer's instructions. The $635 \mathrm{bp}$ amplicons from re-amplification of the randomly chosen colonies using the primers Arch-amoAF and Arch-amoAR were analysed with restriction endonuclease Haelll and Rsal (Bio Basci, Canada). Restriction digestion was carried out in a total volume of $20 \mathrm{ml}$ including $5 \mathrm{U}$ of each restriction enzyme and $4 \mathrm{ml}$ of PCR products, and incubated for $1 \mathrm{~h}$ at $50^{\circ} \mathrm{C}$ and $2 \mathrm{~h}$ at $37^{\circ} \mathrm{C}$ respectively. Digested DNA fragments were analysed by separation of fragments on a $2 \%$ agarose gel and visualized with a GBOX/HR-E-M (Syngene, UK). amoA gene ARDRA patterns were estimated for both of the restriction enzymes and cluster analyses were performed. About 20 representative digestion patterns were observed. And representative clones from each pattern were randomly selected and sequenced with an ABI PRISM 3730 sequencer.

\section{Quantitative real-time PCR}

The copy numbers of archaeal amoA, as well as bacterial amo $A$ gene copy numbers in all samples, were determined in triplicate using an iCycler IQ5 Thermocycler (Bio-Rad, Hercules, CA). The quantification was based on the fluorescent dye SYBR-Green I, which binds to double-stranded DNA during PCR amplification. A total of 40 cycles were run with annealing temperatures and primers as listed in Table 1. Each reaction was performed in a $25 \mu$ l volume containing 1-10 ng of DNA or CDNA, $0.2 \mathrm{mg} \mathrm{ml}^{-1} \mathrm{BSA}, 0.2 \mu \mathrm{M}$ of each primer and $12.5 \mu$ l of SYBR Premix Ex Taq ${ }^{\text {TM }}$ (Takara Shuzo, Shiga, Japan). Product specificity was confirmed by melting curve analysis $\left(65-98^{\circ} \mathrm{C}, 0.2^{\circ} \mathrm{C}\right.$ per read, $6 \mathrm{~s}$ hold) and visualization in agarose gels, which showed specific product bands at the expected size of $c$. $491 \mathrm{bp}$ and $635 \mathrm{bp}$ for the bacterial and archaeal amoA gene respectively.

Archaeal and bacterial amoA gene fragments were cloned as described above, and clones that had the right amo $A$ gene inserts were chosen as the standards for real-time PCR. Plasmid DNA was extracted with Plasmid Kit (TaKaRa), and the plasmid concentration was measured with a spectrophotometer (Nanodrop). As the sequences of the vector and PCR inserts were known, the copy numbers of amoA were calculated directly from the concentration of extracted plasmid DNA (Okano et al., 2004). Ten-fold serial dilutions of a known copy number of plasmid of the $a m o A$ gene clone from the soil were generated to produce the standard curve over seven orders of magnitude $\left(6 \times 10^{2}\right.$ to $6 \times 10^{8}$ copies of template for archaeal $a m o A$ and $1.37 \times 10^{2}$ to $1.37 \times 10^{8}$ copies of template for bacterial amoA) per assay respectively. High amplification efficiencies of 100.7-104.5\% were obtained for archaeal and bacterial amoA quantification with $R^{2}$ values between 0.98 and 0.99 and slopes from -3.2 to -3.3 . Data analysis was carried out with iCycler software (version 1.0.1384.0 CR). The parameter Ct (threshold cycle) was determined as the cycle number at which a statistically significant increase in the reporter fluorescence was detected.

\section{PCR and DGGE analysis of amoA fragments}

For DGGE analysis, DNA and cDNA from RT reactions were amplified with the amoA-1F* and amoA-2R primers set spe-

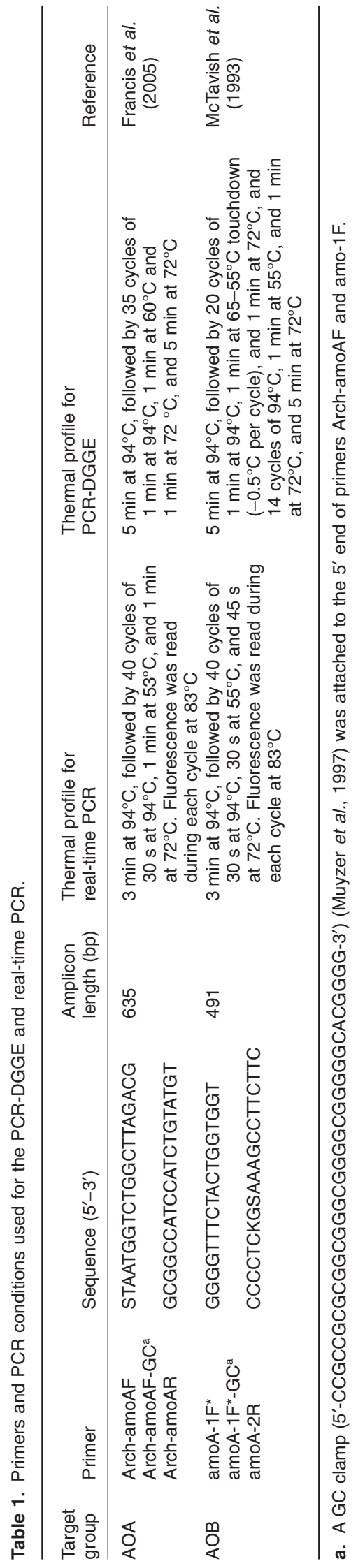


cific for the bacterial amoA gene, and the ArchamoAF and ArchamoAR set specific for archaeal amoA gene. The primer sequence and PCR protocols are listed in Table 1.

Denaturing gradient gel electrophoresis was carried out using a D-Code universal mutation detection system (BioRad Laboratories) according to the instruction manual, and $6 \%(\mathrm{w} / \mathrm{v})$ polyacrylamide [acrylamide-bisacrylamide (37.5:1)] gels containing denaturing gradients of $40-60 \%$ (100\% denaturant containing $7 \mathrm{M}$ urea and $40 \%$ formamide) for separation of PCR products. The gels were stained for $20 \mathrm{~min}$ in ethidium bromide and destained twice for $10 \mathrm{~min}$ in $1 \times \mathrm{TAE}$ buffer [48.22 $\mathrm{g}$ of Tris base, $2.05 \mathrm{~g}$ of anhydrous sodium acetate, and $1.86 \mathrm{~g}$ of disodium EDTA. $2 \mathrm{H}_{2} \mathrm{O}(\mathrm{pH} 8)$ in 1 I of distilled $\mathrm{H}_{2} \mathrm{O}$ ] prior to UV transillumination.

The dominant bands in the DGGE gels were excised, and the acrylamide slices were crushed and re-suspended overnight at $4^{\circ} \mathrm{C}$ in $30 \mu \mathrm{l}$ of sterile water to elute the DNA. Re-amplified PCR products were cloned to E. coli described as above and white colonies were selected for sequencing.

Sequences were compared with GenBank database sequences using BLAST (http://www.ncbi.nlm.nih.gov/ $\mathrm{BLAST} /$ ), and the closest matches were included in the alignment. DNA-DNA sequence similarity percentages were calculated using the sequence similarity matrix function as implemented in BioEdit (freeware by Tom Hall, Department of Microbiology, University of North Carolina). The neighbour-joining trees were constructed using MEGA version 3.1 [Molecular Evolutionary Genetics Analysis (http:// megasoftware.net)] and bootstrapped 1000 times to calculate linear distances.

Sequences of DGGE bands have been deposited with Accession No. EU315701 to EU315711 (bacteria) and EU315724 to EU315734 (archaea). The archaeal amoA gene sequences of the clone library reported here have been deposited in GenBank under Accession No. EU315712 to EU315723.

\section{Data analysis}

Analysis of variance (one-way ANOVA) on plant biomass and archaeal and bacterial amoA gene copy numbers was performed using SPSS 11.5 (SPSS, Chicago, IL). If significant differences were detected $(P<0.05)$, comparisons of means were made using LSD (Least Significant Difference) test.

\section{Acknowledgements}

This study was supported by Natural Science Foundation of China (40621061 and 40671102). We thank Professor F.A. Smith and $\mathrm{Dr}$ M. Cargill for valuable discussion, critical reading and English improvement of this manuscript.

\section{References}

Aoi, Y., Masaki, Y., Tsuneda, S., and Hirata, A. (2004) Quantitative analysis of amoA mRNA expression as a newbiomarker of ammonia oxidation activities in a complex microbial community. Appl Microbiol 39: 477-482.

Arth, I., Frenzel, P., and Conrad, R. (1998) Denitrification coupled to nitrification in the rhizosphere of rice. Soil Biol Biochem 30: 509-515.

Avrahami, S., and Conrad, R. (2003) Patterns of community change among ammonia oxidizers in meadow soils upon long-term incubation at different temperatures. Appl Environ Microbiol 69: 6152-6164.

Avrahami, S., Conrad, R., and Braker, G. (2002) Effect of soil ammonium concentration on $\mathrm{N}_{2} \mathrm{O}$ release and on the community structure of ammonia oxidizers and denitrifiers. Appl Environ Microbiol 68: 5685-5692.

Bedford, B.L., Bouldin, D.R., and Beliveau, B.D. (1991) Net oxygen and carbon dioxide balances in solutions bathing roots of wetland plants. J Ecol 79: 943-959.

Bodelier, P.L.E., Libochant, J.A., Blom, C.W.P.M., and Laanbroek, H.J. (1996) Dynamics of nitrification and denitrification in root-oxygenated sediments and adaptation of ammonia-oxidizing bacteria to low-oxygen or anoxic habitats. Appl Environ Microbial 62: 4100-4107.

Bowatte, S., Jia, Z., Ishihara, R., Nakajima, Y., Asakawa, S., and Kimura, M. (2006a) Molecular analysis of the ammonia oxidizing bacterial community in the surface soil layer of a Japanese paddy field. Soil Sci Plant Nutr 52: 427-431.

Bowatte, S., Ishihara, R., Asakawa, S., and Kimura, M. (2006b) Characterization of ammonia oxidizing bacteria associated with weeds in a Japanese paddy field using amoA gene fragments. Soil Sci Plant Nutr 52: 593-600.

Bowatte, S., Asakawa, S., Okada, M., Kobayashi, K., and Kimura, M. (2007) Effect of elevated atmospheric $\mathrm{CO}_{2}$ concentration on ammonia oxidizing bacteria communities inhabiting in rice roots. Soil Sci Plant Nutr 53: 32-39.

Briones, A.M., Okabe, S., Umemiya, Y., Ramsing, N.B., Reichardt, W., and Okuyama, H. (2002) Influence of different cultivars on populations of ammonia-oxidizing bacteria in the root environment of rice. Appl Environ Microbiol 68: 3067-3075.

Brune, A., Frenzel, P., and Cypionka, H. (2000) Life at the oxic-anoxic interface: microbial activities and adaptations. FEMS Microbiol Rev 24: 691-710.

Cassman, K.G., Kropf, M.J., Gaunt, J., and Peng, S. (1993) Nitrogen use efficiency of rice reconsidered: what are the key constraints? Plant Soil 155/156: 359-362.

De La Torre, J.R., Walker, C.B., Ingalls, A.E., Könneke, M., and Stahl, D.A. (2008) Cultivation of a thermophilic ammonia oxidizing archaeon synthesizing crenarchaeol. Environ Microbiol 10: 810-818.

Francis, C.A., Roberts, K.J., Beman, J.M., Santoro, A.E., and Oakley, B.B. (2005) Ubiquity and diversity of ammoniaoxidizing archaea in water columns and sediments of the ocean. Proc Natl Acad Sci USA 102: 14683-14688.

He, J.Z., Shen, J.P., Zhang, L.M., Zhu, Y.G., Zheng, Y.M., Xu, M.G., and Di, H.J. (2007) Quantitative analyses of the abundance and composition of ammonia-oxidizing bacteria and ammonia-oxidizing archaea of a Chinese upland red soil under long-term fertilization practices. Environ Microbiol 9: 2364-2374.

Horz, H., Barbrook, A., Fields, C., and Bohannan, J.M. (2004) Ammonia oxidizing bacteria respond to multi-factorial global change. Proc Natl Acad Sci USA 101: 1513615141.

Könneke, M., Bernhard, A.E., de la Torre, J.R., Walker, C.B., Waterbury, B., Stahl, D.A., et al. (2005) Isolation of an 
autotrophic ammonia-oxidizing marine archaeon. Nature 437: 543-546.

Kronzucker, H.J., Glass, A.D.M., Siddiqi, M.Y., and Kirk, G.J.D. (2000) Comparative kinetic analysis of ammonium and nitrate acquisition by tropical lowland rice: implications for rice cultivation and yield potential. New Phytol 145: 471-476.

Leininger, S., Urich, T., Schloter, M., Schwark, L., Qi, J., Nicol, G.W., et al. (2006) Archaea predominate among ammonia-oxidizing prokaryotes in soils. Nature 442: $806-$ 809.

Li, Y.L., Fan, X.L., and Shen, Q.R. (2008) The relationship between rhizosphere nitrification and nitrogen-use efficiency in rice plants. Plant Cell Environ 31: 73-85.

McTavish, H., Fuchs, J.A., and Hooper, A.B. (1993) Sequence of the gene coding for ammonia monooxygenase in Nitrosomonas europaea. J Bacteriol 175: 24362444.

Mintie, A.T., Heichen, R.S., Cromack, K., Jr, Myrold, D.D., and Bottomley, P.J. (2003) Ammonia-oxidizing bacteria along meadowto-forest transects in the Oregon Cascade Mountains. Appl Environ Microbiol 69: 3129-3136.

Molina, V., Ulloa, O., Farý'as, L., Urrutia, H., Ramý'rez, S., Junier, P., and Witzel, K.P. (2007) Ammonia-oxidizing $\beta$-proteobacteria from the oxygen minimum zone of northern Chile. Appl Environ Microbiol 73: 3547-3555.

Mosier, A.R., Mohanty, S.K., Bhadrachalam, A., and Chakravorti, S.P. (1990) Evolution of dinitrogen and nitrous oxide from the soil to the atmosphere through rice plants. Biol Fertil Soils 9: 61-67.

Murase, J., Itoh, K., Kano, M., and Kimura, M. (2003) Molecular analysis of $\beta$-proteobacterial ammonia oxidizer populations in surface layers of a submerged paddy soil microcosm. Soil Sci Plant Nutr 49: 909-913.

Muyzer, G., Brinkhoff, T., Nuebel, U., Santegoeds, C., Schafer, H., and Wawer, C. (1997) Denaturing gradient gel electrophoresis (DGGE) in microbial ecology. In Molecular Microbial Ecology Manual, Vol. 3.4.4. Akkermans, A.D.L., Van Elsas, J.D., and De Bruijn, F.J. (eds). Dordrecht, the Netherlands: Kluwer Academic Publishers, pp. 1-27.

Nicolaisen, M.H., Risgaard-Petersen, N., Revsbech, N.P., Reichardt, W., and Ramsing, N.B. (2004) Nitrificationdenitrification dynamics and community structure of ammonia oxidizing bacteria in a high yield irrigated Philippine rice field. FEMS Microbiol Ecol 49: 359-369.

Noll, M., Matthies, D., Frenzel, P., Derakshani, M., and Liesack, W. (2005) Succession of bacterial community structure and diversity in a paddy soil oxygen gradient. Environ Microbiol 7: 382-395.

Okano, Y., Hristova, K.R., Leutenegger, C.M., Jackson, L.E., Denison, R.F., and Gebreyesus, B. (2004) Application of real-time PCR to study effects of ammonium on population size of ammonia-oxidizing bacteria in soil. Appl Environ Microbiol 70: 1008-1016.

Revsbech, N.P., Pedersen, O., Reichardt, W., and Briones, A. (1999) Microsensor analysis of oxygen and $\mathrm{pH}$ in the rice rhizosphere under field and laboratory conditions. Biol Fertil Soils 29: 379-385.

Schleper, C., Jurgens, G., and Jonuscheit, M. (2005) Genomic studies of uncultivated archaea. Nat Rev Microbiol 3: 479-488.

Shen, T.C. (1969) Induction of nitrate reductase and the preferential assimilation of ammonium in germinating rice seedlings. Plant Physiol 44: 1650-1655.

Venter, J.C., Remington, K., Heidelberg, J.F., Halpern, A.L., Rusch, D., Eisen, J.A., et al. (2004) Environmental genome shotgun sequencing of the Sargasso Sea. Science 304: 66-74.

Wang, M.Y., Siddiqi, M.Y., Ruth, T.J., and Glass, A.D.M. (1993) Ammonium uptake by rice roots. I. Fluxes and subcellular distribution of ${ }^{13} \mathrm{NH}_{4}{ }^{+}$. Plant Physiol 103: 12491258.

Wawer, C., and Muyzer, G. (1995) Genetic diversity of Desulfovibrio spp. in environmental samples analyzed by denaturing gradient gel electrophoresis of [NiFe] hydrogenase gene fragments. Appl Environ Microbiol 61: 2203-2210.

Weidner, S., Arnold, W., and Puhler, A. (1996) Diversity of uncultured microorganisms associated with the seagrass Halophila stipulacea estimated by restriction fragment length polymorphism analysis of PCR-amplified 16S rRNA genes: fled 16S rRNA genes. Appl Environ Microbiol 62: 766-771.

Wuchter, C., Abbas, B., Coolen, M.J.L., Herfort, L., van Bleijswijk, J., Timmers, P., et al. (2006) Archaeal nitrification in the ocean. Proc Natl Acad Sci USA 103: 1231712322. 